\title{
Anmerkungen zur Transkription und Übersetzung
}

Türkische Orts- und Personennamen sind nach den Normen des neutürkischen Schriftsystems wiedergegeben. Die türkischen Ortsnamen sind in der Regel entsprechend ihrer gegenwärtigen Form angegeben. Die historischen Ortsnamen werden angemerkt, wenn diese in den Interviews thematisiert werden. Türkische Zitate sind im Original mit den Hervorhebungen wiedergegeben. Während die türkischen Originalzitate in die Fußnoten gesetzt sind, finden sich deren deutsche Übersetzungen im Haupttext.

\section{Aussprache der Buchstaben im türkischen Alphabet}

$\begin{array}{ll}\text { C, c } & {[\mathrm{d} z]} \\ \text { Ç, ç } & {[\mathrm{t}]} \\ \text { G, ğ } & {[:]} \\ \text { I, । } & {[\mathrm{i}]} \\ \text { I, i } & {[\mathrm{i}]} \\ \text { Ş, ş } & {[\mathrm{J}]} \\ \text { S, s } & {[\mathrm{s}]} \\ \mathrm{V}, \mathrm{v} & {[\mathrm{v}]} \\ \text { Y, y } & {[\mathrm{j}]} \\ \text { Z, z } & {[\mathrm{z}]}\end{array}$

\section{Interjektionen}

$\begin{array}{ll}\text { eh } & \text { Ja und, (Zustimmung einforderndes Fragewort) } \\ \text { eh } & \text { äh (Verzögerungslaut) } \\ \text { eh } & \text { hey (Aufforderung, Kontaktaufnahme) } \\ \text { heya } & \text { ja (za.) } \\ \text { vallah } & \text { bei Allah } \\ \text { vallahi } & \text { bei Allah } \\ \text { vay } & \text { oh weh, ach }\end{array}$

\section{Schlüssel zur Transkription der Interviews}

\author{
Wor, abbrechendes Wort \\ Wooort Vokal lang gedehnt \\ I abbrechender Satz \\ \# unverständliches Wort \\ (...) kurze Pause \\ (-) längere Pause \\ [...] längere Passage unverständlich
}




\begin{tabular}{ll} 
[ / ] & Auslassung \\
$\{\ldots\}$ & nicht sicher gehört \\
Wort & Interjektion \\
Wort, Satz & betont \\
\hline$<$ & Stimme hebt sich \\
\rangle & Stimme senkt sich \\
[ ] & Erläuterung der Autorin
\end{tabular}

\section{Hinweis zur Anonymisierung}

Alle Eigennamen sind anonymisiert, wobei alevitische und armenische Eigennamen dementsprechend in andere alevitische und armenische Eigennamen umgeändert wurden. Eigennamen aus Ursprungsmythen und Legenden blieben unverändert. Die Namen der Stammesgemeinschaften sowie Namen von Dörfern und Weilern wurden durch Buchstaben des lateinischen Alphabets ersetzt. Unverändert sind die Namen der Landkreise und Provinzen. 